\section{MENTHOL TREATMENT OF SCREW-WORM}

\section{B. C. DAVIES, M.D. MONROVIA, CAL.}

While it is true that cases of screw-worm from the fly Compsomyia macellaria are rare in the United States, still they do exist and are exceedingly resistant to the treatment outlined in the text-books.

The infection is invariably complicated by the preexistence of an atrophic rhinitis or an ulcerated condition, permitting the larva-screw-worm-to burrow, and thus escape the action of most solutions used to dislodge and destroy it.

Chloroform (in solutions used as a spray and inhalant) is satisfactory and sure for the worms that are hatched and lying in the open, but it does not penetrate sufficiently, neither is its action prolonged enough to destroy the worm, after it has burrowed into the diseased tissues from an atrophic rhinitis, or the egg while it is being hatched.

A thorough curettage of the nasal passages may be done under general anesthetic, but at considerable risk of rupturing blood-vessels and thus affording opportunity for entrance of an embolus or spreading infection to surrounding cavities, in some cases producing death.

After struggling vainly with chloroform in varying solutions-from 20 per cent. to pure chloroform-and thus relieving the patient of some two hundred worms in several treatments, I discovered that the number of worms still increased daily. I therefore realized that I was but collecting the day's hatch, as no worms were visible after using a chloroform spray and picking out the resultant dead ones. Inspired by a recent article on the eradication of the hookworm by the use of menthol, I therefore instituted a treatment with sprays of menthol. Preceding the menthol, peroxid of hydrogen was sprayed into the nose two or three times, the patient blowing his nose freely between applications. Then a 20 per cent. solution of menthol was sprayed into the nostrils very thoroughly under twenty pounds' pressure. Usually within half an hour numbers of the worms were expelled, and in three days, after spraying twice daily, they ceased altogether and showed no return.

Weak solutions were first used but proved useless. The nasal tissue that is in condition to permit growth of this parasite has lost all sense of pain, thus permitting the use of strong solutions.

\section{Therapeutics}

[EDITOR'S NOTE: The following is the first of a series of five articles by Professor Osborne on the revision of the Pharmacopeia. These special articles will take the place of the regular therapeutic matter, which will be resumed on the completion of this series.]

\section{SUGGESTIONS FOR THE PHARMACOPEIA \\ OF 1910}

USEFUL DRUGS OF THE PHARMACOPEIA OF 1900

OLIVER T. OSBORNE, M.D.

Professor of Therapeutics, Yale Medical School NEW HAVEN, CONN.

1. Let the new Pharmacopeia contain such drugs only as are of positive therapeutic value.

2. When a drug or preparation of a drug is prescribed that is not official in the Pharmacopeia of 1910 , let it be officially declared that the standard of purity and the necthod of making preparations not recognized in the Pharmacopeia of 1910 be the standard set and the methods of preparation ordered in the last Pharmacopeia in which the preparation was recognized.

3. Let it contain such new drugs as have been proved of therapeutic value.

4. Let there be issued a supplement to the Pharmacopeia, in 1915, which shall make official such new drugs as have been proved to be of therapeutic value during the years of 1910-1915.

5. Let the 1910 Pharmacopeia give the most simple titles possible to all new drugs, especially to the synthetic drugs. If it is considered impossible, or inadvisable, to make an official title of a drug simple, an official abbreviation should follow the name of the drug.

6. Let the 1910 Pharmacopeia give official approval to only the best of the preparations of the official Galenic drugs, and not officialize the little used and useless preparations of these drugs.

7. Let the 1910 Pharmaeopeia not give official approval of all of the known salts (of iron and mercury, for instance), but officialize only the best. (The Committee on Revision can just as well decide this question as it can decide the new drugs that are worthy of a place in the United States Pharmacopeia, or as it can decide the strength a tincture shall have, and certainly the tinctures - were radically changed in the 1900 U. S. P., whether everyone was pleased or not.)

8. Let the average adult dose appear after each drug and each preparation of it, not the range of dose, i. e., minimum to maximum, as there is no exact under or over limit of dose. The dose is enough to accomplish the object aimed at by the prescriber, and all he cares to know is the average dose.

9. As the U. S. P. gives the official titles of drugs in Latin, it should also give the genitive after each title. This would be of especial value in teaching the correct writing of prescriptions. It is not always easy to determine the declension to which a Latin noun belongs, or whether it may not be indeclinable.

10. Let the official preparations of a drug be enumerated under the title of that drug.

\section{DUSTING POWDERS}

The dusting powders may be named as acetanilid combinations, bismuth preparations, boric acid alone or combined, various preparations containing iodin in some form, and the more simple powders, such as lycopodium, talcum, zinc oxid and zinc stearate.

It would seem hardly necessary, with all of the powders that are official, to prescribe, for a dressing, one that is not official. But even among physicians there is a tendency to appeal to the unknown and the mysterious, hoping that a lauded proprietary powder will heal a wound inore quickly than something the ingredients of which is known. This is probably the reason that so many nostrum powders are prescribed. It should be remembered that dermatol is official under the name of bismuth subgalate, and that aristol is official under the name of thymol iodid (thymolis iodidum). The fo'lowing simple combination is probably as good a drying antiseptic powder as can be ordered:

R.

Acidi salicylici $\ldots \ldots \ldots \ldots \ldots, \ldots \ldots \ldots, 1$

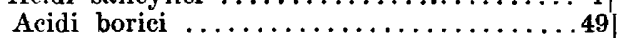

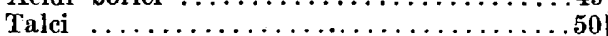

or $\mathrm{gr} . \mathrm{xx}$ $\overline{\mathbf{a}} \overline{\mathbf{a}}, \bar{\zeta} \mathrm{ii}$

M. et Sig.: Use externally as a dusting powder or dressing.

It should be declared, although by some surgeons it will be considered a heresy, that the intensely cbnoxious 